\title{
Hyperbranched Polymers as Delivery Vectors for
}

\section{Oligonucleotides}

Jian Hong Tan ${ }^{1}$, Nigel A. J. McMillan ${ }^{2}$, Elizabeth Payne ${ }^{2}$, Cameron Alexander ${ }^{3}$,Felicity Heath ${ }^{3}$, Andrew K Whittaker ${ }^{1}$ and Kristofer J Thurecht ${ }^{1}$ *

${ }^{1}$ Australian Institute for Bioengineering and Nanotechnology and Centre for Advance Imaging, The University of Queensland, St Lucia, Queensland 4072, Australia.

${ }^{2}$ The University of Queensland Diamantina Institute, The University of Queensland, Research Wing, Building 1 Princess Alexandra Hospital, Woolloongabba, Queensland, 4102, Australia.

${ }^{3}$ School of Pharmacy, The University of Nottingham, Nottingham, NG7 2RD, United Kingdom

k.thurecht@uq.edu.au

RECEIVED DATE (to be automatically inserted after your manuscript is accepted if required according to the journal that you are submitting your paper to)

Dr Kristofer J Thurecht.

Australian Institute for Bioengineering and Nanotechnology and

Centre for Advanced Imaging

The University of Queensland

St Lucia 4072 
QLD Australia

Ph: +6133463864

Email: k.thurecht@uq.edu.au

We report on the synthesis and characterization of hyperbranched dimethylaminoethyl methacrylate (DMAEMA) polymers using reversible addition fragmentation chain-transfer (RAFT) polymerization. These polymers were shown to effectively bind and condense oligonucleotides (ODNs) as a model system for siRNA binding; visualization of the bound complexes was achieved using atomic force microscopy while isothermal titration calorimetry described the thermodynamics of binding. The ODNs were effectively protected from enzymatic degradation (DNAses) when condensed by all the polycations studied. However, transfection into HeLa cells was less effective when the polycation was chain extended with polyethyleneglycol monomethylether methacrylate. Conjugation of folic acid to the periphery of the polycation facilitated much enhanced uptake of the oligomeric DNA into the HeLa cells due to overexpression of folate receptors on the surface of HeLa cells. Although significant cytotoxicity was observed at high polymer concentrations, this could be alleviated by shielding of the polycation using polyethyleneglycol monomethylether methacrylate (PEGMA). These results suggest that hyperbranched polymers formed in this way have high promise as gene delivery vectors.

Keywords. Hyperbranched polymer, gene delivery, RAFT polymerization.

\section{Introduction.}

The spontaneous self-assembly of block copolymers in selective solvents has received increasing interest over the previous decade. This has been partly fueled by the use of these nanoparticle assemblies in biomedical applications such as drug delivery and diagnostic imaging. ${ }^{1}$ However, a fundamental problem encountered with block copolymer micelles is that below the critical micelle concentration $(\mathrm{cmc})$, the nanostructures undergo spontaneous dissociation. ${ }^{2}$ This can have particular 
importance in biomedical applications when micellar solutions are injected into the vast blood pool and micellar stability cannot be guaranteed. In the past, this has been overcome by crosslinking the preformed micelles either in the core (core crosslinked - CCL) ${ }^{3}$, or at the corona (shell crosslinked - SCL) ${ }^{4}$ of the particle. This imparts a degree of "shape-persistence" to the particle, even below the cmc. Herein, we report on a further method of synthesizing shape-persistent nanoparticles in a facile, single pot reaction; hyperbranched block copolymers.

Hyperbranched polymers have often been dubbed the poor cousin of dendrimers. While the cost, and most certainly the synthetic challenge, of developing hyperbranched polymers is considerably lower than that of the much more structurally symmetrical dendrimer, hyperbranched polymers still exhibit many of the overall properties of a dendrimer. ${ }^{5}$ Perhaps the most important of these is the presence of a high degree of functionality both at the surface of the particle and within the branched interior. Various techniques for building up high molecular weight hyperbranched polymers by free radical techniques, without inducing macromolecular gelation, have emerged over the previous decade ${ }^{5-9}$ and these have been reviewed previously. ${ }^{10}$ For the case of reversible addition fragmentation chain-transfer polymerization (RAFT), Perrier et al. showed that highly branched polymers could be synthesized up to high monomer conversion. ${ }^{11-12}$ No matter the method of synthesizing these polymers, the use of controlled radical polymerization techniques have allowed the development of highly-branched molecules having properties akin to those of their dendritic cousins, using a simple reaction procedure.

One of the most promising routes for cancer therapy that has evolved in the last decade is the use of small-interfering RNA (siRNA) as a means of "switching-off" genes. ${ }^{13}$ siRNA acts by down-regulation of a target mRNA via the interference pathway. In only 10 years, research into siRNA for therapy (especially cancer related therapies) has increased dramatically. However, while siRNA and gene therapy provides a real alternative to conventional chemotherapies, significant hurdles related to the delivery and efficacy of treatment must still be overcome before this technology can be used as a treatment of cancer. ${ }^{14-15}$ Of particular importance is the poor in vivo stability and insufficient intracellular uptake of siRNA, thus, there is an enormous research effort aimed at developing possible 
carrier systems for siRNA. Two of the most common approaches for enhanced gene delivery utilize viral or non-viral delivery vectors. Each exhibits various advantages and disadvantages as carrier systems. For example, viral vectors can elicit an immune response which is detrimental for gene delivery, while non-viral vectors must be chemically synthesized to be biocompatible and noncytotoxic. Non-viral polymeric carriers for siRNA have received particular attention recently and these will be the focus of this report ${ }^{16}$.

It has previously been reported that the molecular structure of polymeric carriers for DNA delivery greatly affects transfection efficiency. ${ }^{17}$ Thus, in this paper, we report on the synthesis of hyperbranched polymers of poly(dimethylaminoethyl methacrylate) (PDMAEMA) that have been chain extended with poly(ethyleneglycol monomethylether methacrylate) (PEGMA) using free radical chemistry. The cytotoxicity of PDMAEMA has been clearly demonstrated in vitro ${ }^{18}$ (both linear and branched) and it has been further shown that the polymer can be rendered biocompatible by pegylation by masking the cationic charge. ${ }^{19}$ In this report we investigate the binding efficiency of each class of hyperbranched polymer with ODNs using isothermal calorimetry (ITC), atomic force microscopy (AFM) and gel electrophoresis (PAGE). Additionally, the ability of the hyperbranched polymer to effectively protect the oligonucleotides from enzymatic attack has been investigated. In a final example, folic acid was conjugated to the periphery of the polycation to investigate whether a specific receptor-targetting moiety influences the efficiency of the cellular uptake of the complexes in HeLa cells. The applicability of these particles as gene delivery vectors is discussed.

\section{Materials and Methods.}

Materials. Dimethylaminoethyl methacrylate (DMAEMA), ethyleneglycol dimethacrylate (EGDMA) and poly(ethylene glycol monomethyl ether methacrylate) (PEGMA, MW = 475) were obtained from Sigma and passed through an alumina column to remove inhibitor prior to use. 2,2'Azobisisobutyronitrile (AIBN) was purchased from Acros and recrystallized three times from methanol. Dodecylsulfanylthiocarbonylsulfanyl-2-methyl propionic acid (CTA) was synthesized as previously 
reported. $^{20}$ Short linear DNA for AFM studies was obtained from Sigma (DNA sodium salt from Salmon testes; $2 \mathrm{kbp})$. 9-27 Oligo was purchased from Invitrogen (9-27F+R; 23bp) having the following configuration:

Sense: $\quad$ 5' GTCAGAAATAGAAACTGGTCATC 3'

Antisense: GATGACCAGTTTCTATTTCTGAC

Synthesis of Hyperbranched DMAEMA (P1). The general procedure for the synthesis of hyperbranched DMAEMA was taken directly from the work of Perrier et al. ${ }^{11}$ The ratio of DMAEMA:EGDMA:CTA:AIBN used was 100:5:5:0.5. The reactants were degassed by three consecutive freeze-pump-thaw cycles and the reaction was conducted in THF at $65{ }^{\circ} \mathrm{C}$ for 48 hours.

Synthesis of Hyperbranched DMAEMA-b-PEGMA (P2). In a typical copolymerization experiment, 0.5 g hyperbranched DMAEMA was dissolved in THF with $3 \mathrm{mg}$ AIBN and 2 g PEGMA. The solution was degassed by three freeze-pump-thaw cycles and then stirred at $65{ }^{\circ} \mathrm{C}$ for 24 hours. The product was precipitated in diethyl ether and dried under vacuum overnight. ${ }^{1} \mathrm{H}$ NMR $\left(\mathrm{CDCl}_{3}\right)$ 0.9-1.2 ppm (br m, CH backbone); 0.9ppm (br, CH2CH3); 1.17-1.47 ppm (SCH2C11H20); 1.7-2 ppm (br m, $\mathrm{CH} 2 \mathrm{CH}) ; 2.2 \mathrm{ppm}(\mathrm{s}, \mathrm{N}(\mathrm{CH} 3) 2) ; 2.62 \mathrm{ppm}(\mathrm{br} \mathrm{t}, \mathrm{CH} 2 \mathrm{CH} 2 \mathrm{~N}) ; 3.35 \mathrm{ppm}(\mathrm{s}, \mathrm{OCH} 3) ; 3.5-3.6 \mathrm{ppm}(\mathrm{m}$, $\mathrm{CH} 2 \mathrm{CH} 2 \mathrm{O}$ ); 3.95ppm (br t, $\mathrm{COOCH} 2 \mathrm{CH} 2) ; 4.1 \mathrm{ppm}($ br t, $\mathrm{CH} 2 \mathrm{CH} 2 \mathrm{~N}) ; 4.7 \mathrm{ppm}(\mathrm{s}, \mathrm{CH} 2 \mathrm{CCH})$.

\section{Synthesis of Folate-decorated Hyperbranched DMAEMA (P3). The alkyne-terminated DMAEMA} was first chain extended with a short PEG unit ( $\alpha$-amino, $\omega$-azide trimer) which was subsequently reacted with folic acid. In a typical procedure, $0.5 \mathrm{~g}$ P1 $\left(7.3 \times 10^{-6} \mathrm{~mol}\right.$ polymer, $3.6 \times 10^{-5}$ mol alkyne groups) and $10.9 \mathrm{mg}$ 11-azido-3,6,9-trioxaundecan-1-amine $\left(5 \times 10^{-5} \mathrm{~mol}\right)$ was dissolved in a $1: 1$ mixture of water and THF. $25 \mu \mathrm{L}$ of a $0.2 \mathrm{M}$ sodium ascorbate solution and $25 \mu \mathrm{L}$ of a $0.1 \mathrm{M} \mathrm{Cu}(\mathrm{II}) \mathrm{SO}_{4}$ solution were added and the solution was stirred at room temperature for 24 hours. The reaction mixture was filtered through a plug of neutral alumina to remove the copper followed by dialysis against water for 3 days in a dialysis cassette with $3.5 \mathrm{kDa}$ molecular weight cut off. The resulting polymer was freeze-dried to yield a slightly yellow powder. 
The folic acid was attached to the polymer via standard EDC coupling. $0.25 \mathrm{~g}$ of the clicked P1 synthesized above was added to $44 \mathrm{mg}$ of folic acid ( $1 \times 10^{-4}$ moles $), 31 \mathrm{mg}$ EDC ( $\left.2 \times 10^{-4}\right)$ and $5 \mathrm{~mL}$ dry DMF. The reaction mixture was stirred at room temperature for 24 hours and then dialysed against water for 5 days. The freeze-dried product was a yellow powder. Folic acid conjugation was quantified by UV-VIS spectroscopy.

Gel permeation chromatography (GPC) was performed using a Waters 333 system fitted with an RI detector. Two Styragel HT3 columns were attached in series and eluted with DMF at a flow rate of 1 $\mathrm{mL} / \mathrm{min}$ at $40{ }^{\circ} \mathrm{C}$. A Dawn 8 -angle MALLS detector from Wyatt Technologies was used for light scattering experiments. The Astra software package for Windows was used to process the data.

Atomic force microscopy (AFM) was performed on an MFP 3D (Asylum Research) microscope. Typically, polymer samples were dissolved in buffer of desired $\mathrm{pH}$ to a concentration of around 0.05 $\mathrm{mg} / \mathrm{mL}$. DNA or RNA was then added followed by gentle shaking for 5 minutes. The sample was spotted onto a freshly cleaved mica surface, incubated for 2 minutes followed by washing with buffer. The sample was then dried overnight in a desiccator before analysis. The cantilevers used were HA_NC (Etalon) from NT-MDT, Russia having a nominal spring constant of $5.6 \mathrm{~N} / \mathrm{m}$ and a nominal resonant frequency of $200 \mathrm{kHz}$. All the images were obtained by employing the Tapping Mode of the AFM in air. The AFM is mounted on an anti-vibration table (Herzan) and operated within an acoustic isolation enclosure (TMC, USA).

Isothermal titration calorimetry (ITC) was performed on an ITC200(MicroCal, Northampton, MA, USA). $1 \mathrm{mM}$ phosphate buffer was used as solvent for the polymer and DNA and also as the reference for the ITC measurements. For P1, a $6 \mathrm{mM}$ solution of polymer was titrated into $200 \mu \mathrm{L}$ of $0.375 \mu \mathrm{M}$ solution of DNA in $20 \mu \mathrm{L}$ aliquots and the heat associated with binding and condensation was measured. The same protocol was used for P2, however the concentrations of the polymer and DNA solutions were $15 \mathrm{mM}$ and $0.187 \mu \mathrm{M}$, respectively. A single site binding model was used to fit the data in all cases to yield an estimate of the binding constant (K), the number of binding sites (n) and the enthalpy of binding $(\Delta \mathrm{H})$. The integrated heats of binding were corrected for enthalpy of dilution by 
running a reference scan consisting of the addition of polymer solution to pure buffer. In all cases, the enthalpy associated with dilution is much less than the enthalpy of binding-condensation.

Transmission Electron Microscopy (TEM) was conducted on a Philips Technai $120 \mathrm{kV}$ instrument equipped with a cryo-stage for low temperature observation. In a typical experiment, hyperbranched polymer was dissolved in water at a concentration of $0.05 \mathrm{mg} / \mathrm{mL}$. A drop of this solution was placed on a holey carbon grid and then dabbed dry with filter paper. The grid was then plunged in liquid nitrogen for 2 minutes before transferring onto the cryo-stage and insertion into the instrument.

${ }^{1}$ H Nuclear magnetic resonance spectroscopy $\left({ }^{1} \mathbf{H}\right.$ NMR) was undertaken on a Bruker Avance 300 spectrometer. $\mathrm{CDCl}_{3}$ or $\mathrm{d}_{6}$-DMSO were generally used as solvent for the hyperbranched polymers as described in the text.

\section{Binding Assay.}

In a standard assay, $1.0 \mu \mathrm{g}$ of naked DNA oligonucleotide (9-27 Oligo) was complexed with polymer at $\mathrm{N}: \mathrm{P}$ ratios from 10 to 200 in a total volume of $100 \mu \mathrm{L}$ of $\mathrm{pH}=5.5$ acetate buffer and allowed to mix for $30 \mathrm{~min}$ at room temperature. Next, $25 \mu \mathrm{L}$ of complexed oligo:polymer was mixed with $5 \mu \mathrm{L}$ of DNA loading dye, loaded into a 2\% TAE-agarose gel containing $100 \mathrm{ng} / \mathrm{ml}$ ethidium bromide and the gel electrophoresed in 1xTAE for approximately 10 minutes at $80 \mathrm{~V}$ before the gel was visualized using UV transillumination.

Protection Assay. Typically, $1.0 \mu \mathrm{g}$ of naked DNA oligo (9-27 Oligo) was complexed with polymer at $\mathrm{N}: \mathrm{P}$ ratios from 10 to 200 in a total volume of $100 \mu \mathrm{L}$ of $\mathrm{pH} 5.5$ acetate buffer and allowed to complex for $30 \mathrm{~min}$ at room temperature. Fifty $\mu \mathrm{L}$ of DNAse solution, containing 1.5U DNase in provided buffer (New England Biolabs), was added to each sample and samples incubated at $37{ }^{\circ} \mathrm{C}$ for a further 10 minutes. DNA oligonucleotides were extracted using phenol/chloroform (1:1, Amresco) before loading onto a $12 \%$ non-denaturing polyacrylamide gel run in 1xTBE for approximately 1 hour at 100V. DNA was visualized by staining the gel with ethidium bromide for 5-15 minutes followed by UV transillumination. 
Transfection Protocol. HeLa cells were seeded in 24-well plates to a density of $5 \times 10^{4}$ cells per well. The following day, $4 \times 10^{-11}$ mole FITC-Oligo was added to $\mathrm{H}_{2} \mathrm{O}$ to a maximum volume of $50 \mu \mathrm{L}$ and complexed with the desired volume of polymer to make N:P ratios of 10-200. The polymer-Oligo mixture was left to incubate for 30 minutes and then OptiMem or antibiotic-free DMEM was added to make the final volume $1 \mathrm{~mL}$. The cells were washed once with PBS then $250 \mu \mathrm{L}$ of the polymer-oligo mixture was added to each well and the cells were incubated for 4 hours. The complex solution was removed, cells washed with PBS and the cells treated with trypsin, washed once with PBS and collected by centrifugation at $3000 \mathrm{~g}$ for 2 minutes. Finally, the cells were resuspended in $0.2-0.5 \mathrm{~mL} 2 \%$ paraformaldehyde before analysis by fluorescence-activated cell sorting (FACS).

\section{Results and Discussion}

Synthesis and characterization of hyperbranched polymers. The synthesis of hyperbranched polymers using controlled free radical chemistry has recently received considerable interest, due mainly to the broad range of functionalities available in this mode of polymerization. Recent work has shown that the use of various controlling agents facilitates much greater control in free radical systems by controlling the rate of branching without gelation, since each polymer chain is growing in a controlled manner. ${ }^{10}$ These polymers are termed hyperbranched polymers. In this paper, RAFT agents were used to mediate the chain growth and branching in these polymers. While the cytotoxicity of RAFT-capped polymers may not be fully understood and will undoubtedly depend on a specific application, facile work-up and the absence of any metal catalysts in the final polymer (as might be present with other living polymerization techniques such as atom-transfer radical polymerization, for example) makes RAFT agents a particularly enticing approach for synthesizing polymers for biomedical applications.

The synthesis of hyperbranched polymers using RAFT was originally reported by Perrier et al. ${ }^{11}$ and a recent review covers the broad range of techniques used to design such polymers. ${ }^{10} \mathrm{~A}$ schematic diagram showing the different structures synthesized in this study is shown in Scheme 1. Hyperbranched DMAEMA was synthesized using an alkyne-terminated RAFT agent in order to 
facilitate "click" chemistry for further functionalization of the polymer. Chain-extension to form hyperbranched DMAEMA-block-PEG was then performed by radical polymerization of PEGMA from the RAFT end-groups of the hyperbranched polycation.

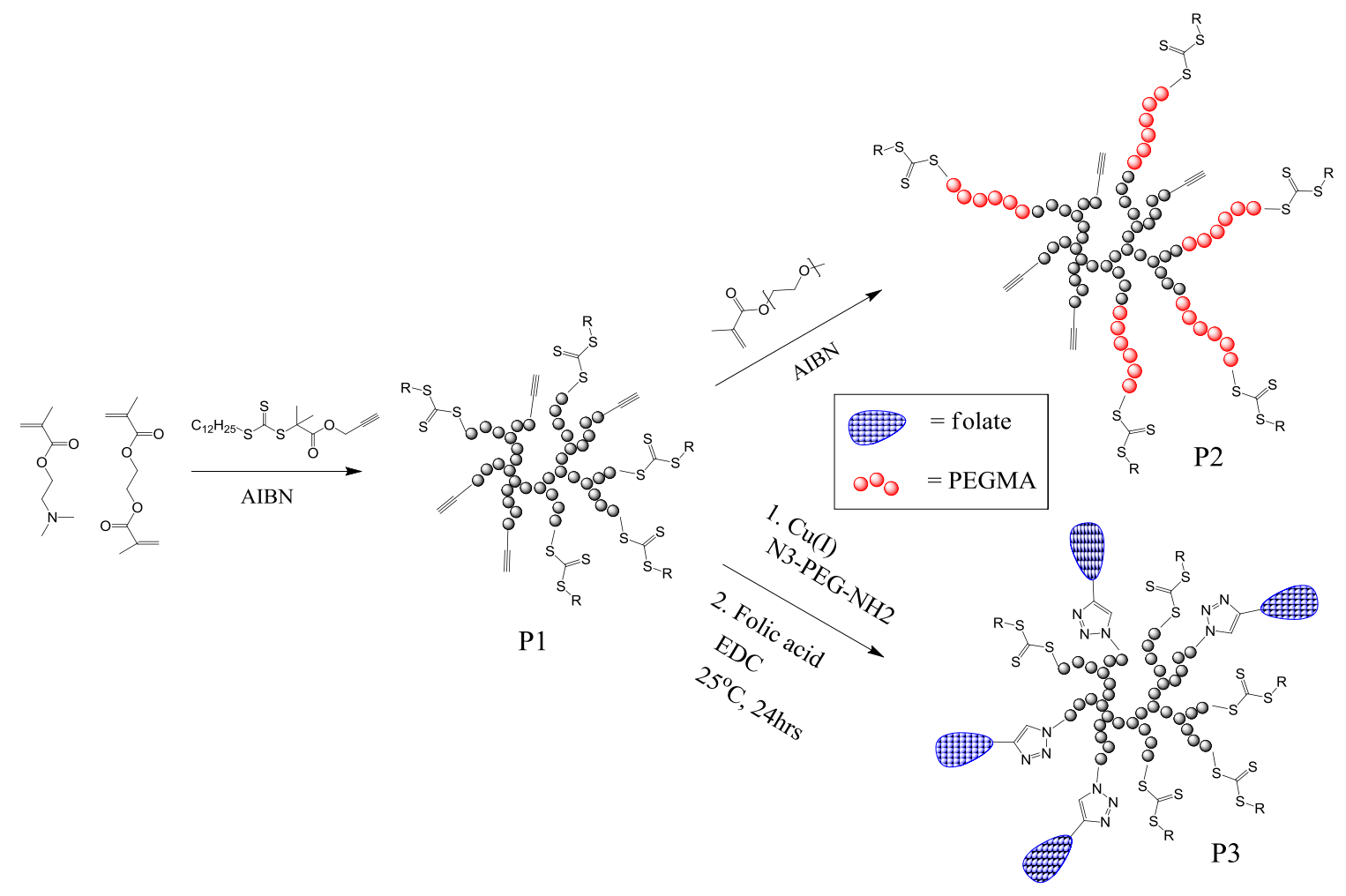

Scheme 1. Scheme outlining the synthesis of hyperbranched DMAEMA (P1), hyperbranched DMAEMA-b-PEGMA (P2) and folate-labeled hyperbranched DMAEMA (P3).

In a typical experiment, the molecular weight profile of the polymer as a function of monomer conversion evolves from a single, monomodal peak in the GPC trace to a broad and multimodal GPC distribution. This is characteristic of hyperbranched polymers and describes the random coupling of chains through statistically distributed branching agents. Figure 1 shows the molecular weight evolution of hyperbranched DMAEMA as measured by GPC with a refractive index (RI) detector. The final polymer after 48 hours had a broad polydispersity (3.8). 


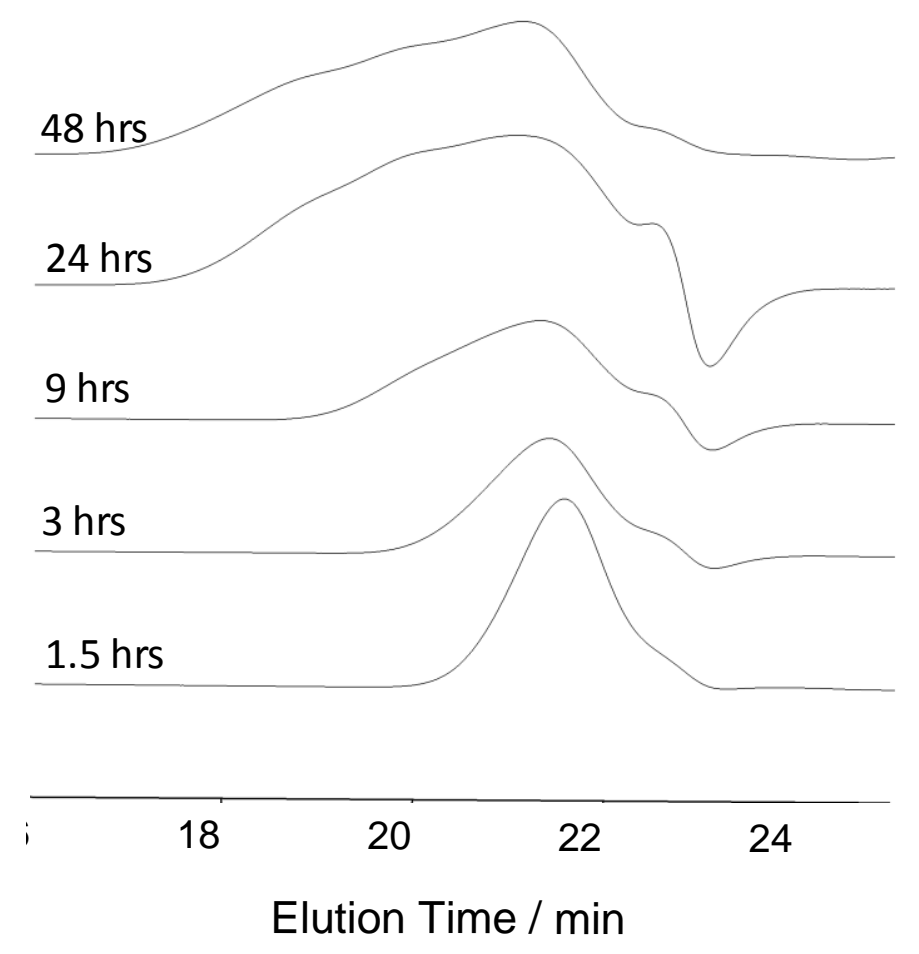

Figure 1. GPC traces (RI detector) of P1 during polymerization as a function of time. The traces move to shorter elution time (and hence higher molar mass) and become broad and multimodal as polymerization progresses.

GPC-MALLS is a useful tool for showing the existence of branching within a polymer. Light scattering detectors allow absolute determination of molecular weight of a polymer, irrespective of the hydrodynamic radius of that polymer in solution. Figure 2 shows a plot of molecular weight as a function of elution time for a sample of hyperbranched and linear DMAEMA as determined by light scattering. The RI trace for each polymer is also shown to highlight the elution volumes over which molar masses are calculated. Linear polymers adopt a random coil conformation in a good solvent whereas branched polymers tend towards a much more compact structure. Indeed, highly branched polymers can often adopt a spherical conformation. Thus, for standard SEC analysis, which bases separation on the hydrodynamic radius of the polymer chains in a good solvent, branched polymers will have a molecular weight much greater than linear polymers at a specific elution volume. To illustrate 
this point, Figure 2 compares the RI chromatograms (dashed lines) to the absolute molecular weight as determined by MALLS for a hyperbranched polymer (P1) and linear analogue. The molecular weight of the hyperbranched polymer is much higher than that for the linear sample at all elution volumes. For example, at an elution time of $20 \mathrm{~min}$ in Figure 2, the molecular weight of linear DMAEMA is approximately $10 \mathrm{kDA}$, however it is $100 \mathrm{kDa}$ for the hyperbranched molecule. This provides evidence that the molecules are more compact, and hence branched, than the linear molecule.

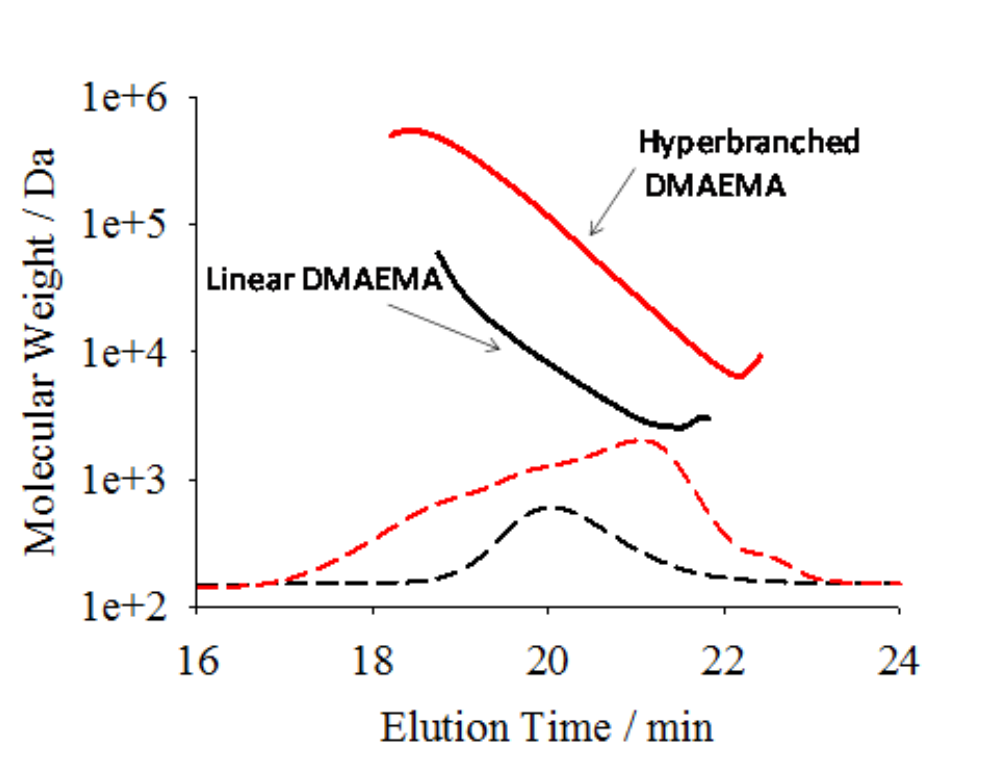

Figure 2. Molecular weight versus elution time plots (solid lines) for hyperbranched (P1 Table 1, Entry 1; Figure 1. $48 \mathrm{hrs)}$ and linear DMAEMA. The RI traces for each polymer is shown as dashed lines. The hyperbranched polymer has a much higher molar mass than the linear polymer at the same elution time due to the much more compact nature of the hyperbranched macromolecule in solution.

A typical ${ }^{1} \mathrm{H}$ NMR spectrum of the hyperbranched DMAEMA is shown in Figure 3. By comparison of the integrals of the signals due to the RAFT end-groups and DMAEMA monomer units, the molar mass of each chain run length (excluding branch points) was calculated to be $14.5 \mathrm{kDa}$. Thus, the number of chain ends (and hence branch points) can be calculated by dividing the absolute molar mass of the hyperbranched molecule by the molar mass of the run length excluding branch points (i.e. Mn(MALLS)/Mn(NMR)). ${ }^{19}$ Based on a number average, the hyperbranched polymer P1 has five alkyne end-groups and five thio-carbonyl-thio end groups (Table 1). 


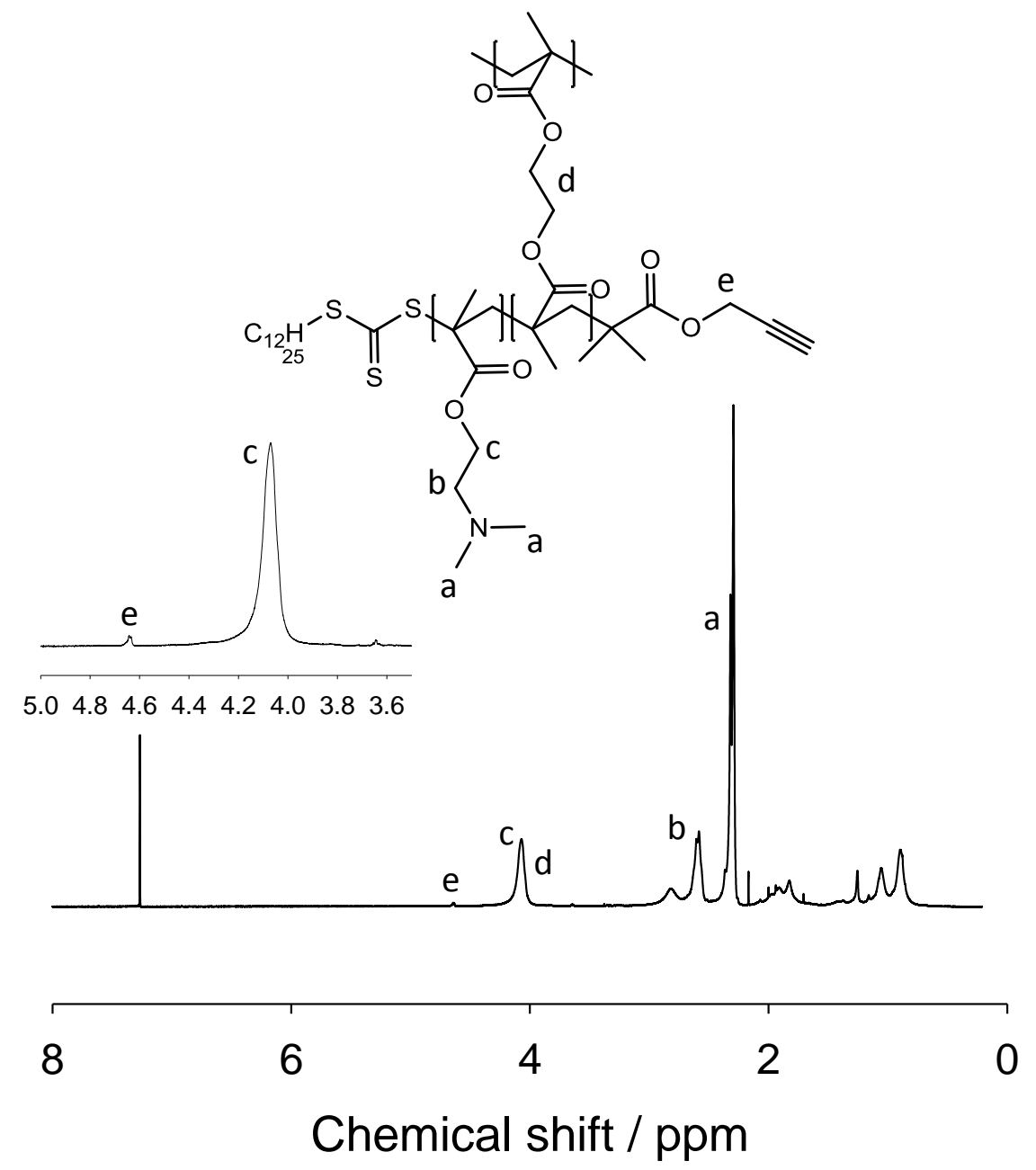

Figure 3. ${ }^{1} \mathrm{H}$ NMR spectrum of hyperbranched DMAEMA highlighting signals from the RAFT endgroup (methylene adjacent to alkyne group - peak e) and DMAEMA units (peaks b and c).

Chain extension of the homopolymer hyperbranches was conducted by continuation of the polymerization with PEGMA using THF as solvent (P2 Scheme 1, Table 1). The molar mass of the chain-extended polymer was determined using GPC-MALLS and the number average ratio of DMAEMA:PEGMA using ${ }^{1} \mathrm{H}$ NMR. The number of PEGMA chains emanating from the hyperbranched core was calculated by the ratio of molar mass of chain extended PEGMA as determined by GPCMALLS (i.e. $\left.\left(\mathrm{M}_{\mathrm{n}(\mathrm{P} 2)}-\mathrm{M}_{\mathrm{n}(\mathrm{P} 1)}\right) / \mathrm{M}_{\mathrm{n}(\mathrm{NMR})}\right)$ to the molar mass of PEGMA as determined by ${ }^{1} \mathrm{H}$ NMR $(\sim 4.5$ $\mathrm{kDa})$. 
In addition, hyperbranched polymer $\mathrm{P} 1$ was functionalized with folic acid (P3 Scheme 1, Table 1) to investigate whether receptor-mediated endocytosis would improve cell uptake of the polymers. The number of folic acid molecules conjugated to each hyperbranched polymer was calculated by measuring $\lambda_{\max }$ at $363 \mathrm{~nm}$ and the molar extinction coefficient of folate set to $6.5 \times 10^{3} \mathrm{M}^{-1} \mathrm{~cm}^{-1}$. The molecular characteristics of each polymer are presented in Table 1.

Table 1. Molecular characteristics of the polymers shown in Scheme 1.

\begin{tabular}{c|ccc|c|c|c}
\hline Polymer & \multicolumn{3}{|c|}{ MALLS Detector } & Size / nm & Zeta potential / $m V$ & No. End Groups \\
& $\mathrm{M}_{\mathrm{n}} / \mathrm{kDa}$ & $\mathrm{M}_{\mathrm{w}} / \mathrm{kDa}$ & $\mathrm{Ð}_{\mathrm{m}}$ & (Width/nm) & \\
\hline $\mathrm{P} 1^{\mathrm{a}}$ & 67 & 111 & 1.6 & $12.3(3.5)$ & +32.1 & $5.2^{\mathrm{d}}$ \\
$\mathrm{P} 2^{\mathrm{b}}$ & 82 & 182 & 2.2 & $18.0(5.6)$ & +1.3 & $\sim 3^{\mathrm{e}}$ \\
$\mathrm{P} 3^{\mathrm{c}}$ & 68 & 121 & 1.8 & $13.1(4.1)$ & +7.25 & $\sim 5^{\mathrm{f}}$ \\
\hline
\end{tabular}

${ }^{\mathrm{a}} \mathrm{dn} / \mathrm{dc}$ P1 $=0.059 ;{ }^{\mathrm{b}} \mathrm{dn} / \mathrm{dc} \mathrm{P} 2=0.048 ;{ }^{\mathrm{c}} \mathrm{dn} / \mathrm{dc} \mathrm{P} 3=0.055 ;{ }^{\mathrm{d}} \mathrm{M}_{\mathrm{n}(\mathrm{MALLS})} / \mathrm{M}_{\mathrm{n}(\mathrm{NMR})} ;{ }^{\mathrm{e}} \mathrm{Calculated}$ based on ratio of PEGMA:DMAEMA in ${ }^{1} \mathrm{H}$ NMR and $\mathrm{M}_{\mathrm{n} \text { (MALLS); }}{ }^{\mathrm{f}}$ Calculated from UV-VIS spectrometry by measuring absorption at $363 \mathrm{~nm}$ using $\varepsilon=6500 \mathrm{M}^{-1} \mathrm{~cm}^{-1}$.

Particle size characterization. The size of the hyperbranched polymers, and how they interact in solution, will determine their potential as gene and/or drug delivery agents. Information on factors such as swollen particle size and degree of agglomeration - if any - will provide information critical for understanding factors such as cell uptake rates and release profiles of drugs, for example. The particle size and size distribution was determined by DLS and cryo-TEM analysis.

DLS provides information on the hydrodynamic radius of the macromolecules in solution. The size of each of the hyperbranched molecule in pure water as determined by DLS is presented in Table 1. The size of the polymers were found to lie between $10-20 \mathrm{~nm}$. There is also a small population of large particles in the range of several hundreds of $\mathrm{nm}$ which is assigned to aggregates in solution. It is also evident from the DLS that the particle size increases as the hyperbranched DMAEMA core (Entry 1, Table 1) is chain-extended with PEGMA ( 4 kDa arms, Entry 2, Table 1) or extended with folic acid via click chemistry (Entry 3, Table 1). 
CryoTEM is a powerful tool for the visualization of the hyperbranched particles as they appear in solution and is typically devoid of agglomeration artefacts that are observed in deposition-evaporation TEM analysis due to concentration effects. Hyperbranched DMAEMA-b-PEGMA particles (P2) were dissolved in tris-buffer at pH 7.0 and an aqueous film was frozen in liquid nitrogen on a holey carbon grid and immediately examined by TEM. A typical image is presented in Figure 4.

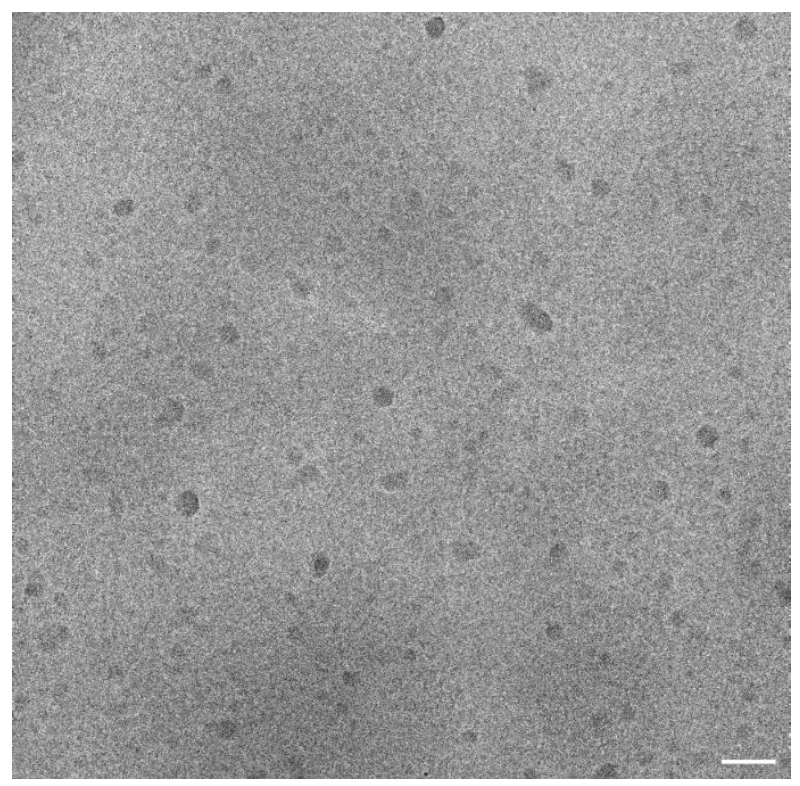

Figure 4. CryoTEM image of hyperbranched DMAEMA chain extended with PEGMA. The scale-bar is $50 \mathrm{~nm}$. Additionally, the compact nature of the hyperbranched molecules gives them a spherical conformation in solution.

The particles in Figure 4 were frozen in vitreous ice. Due to the similar electron densities of the two components of the copolymer, contrast between the two polymers is not evident in these images. However, the particle sizes are in the range of 10-20 nm. This concurs with the sizes measured by DLS for hyperbranched DMAEMA-block-PEGMA.

\section{Polymer-DNA complexes}

Isothermal calorimetry (ITC) was used to investigate the thermodynamics of polycation-DNA interactions. Numerous authors have investigated the thermodynamics and mechanism of bindingcomplexation of polymeric cations with DNA. In this case, we have utilized a simple single-site binding 
model. While it has been suggested that in fact a more complex mechanism of binding-condensation of the DNA to polycations is likely, ${ }^{21}$ the single-site model provides a convenient method to examine qualitatively the differences in binding events for our polycationic systems. Furthermore, direct comparison of our results, to those previously published for linear DMAEMA by other authors using the single-site model is possible. ${ }^{22}$

In these experiments, short DNA sequences (9-27 Oligo) were used to mimic the solution properties of siRNA. Due to the highly branched structure of the hyperbranched macromolecules, it was expected that under specific conditions, some of the positive charges on the DMAEMA would be inaccessible for binding with the negative phosphate groups on the DNA. Indeed, a plot of enthalpy of binding versus the molar N:P ratio for pure hyperbranched DMAEMA (Table 1, Entry 1) at pH 5.5 shows that equilibrium binding occurs (i.e. there is no further change in enthalpy upon further addition of DNA) at a nitrogen to phosphorous ratio (N:P) of approximately 1.1 (Table 2, Entry 1; Figure 5a). This suggests that there are a small number of amine groups within the hyperbranched molecule that are not effectively presented at the surface of the molecule for binding. An alternative explanation for this deviation from unity might be that the polydispersity of the molecule leads to errors in the calculation of the N-concentration since $M_{n}$ was determined from GPC-MALLS measurements. The thermodynamic parameters as determined by ITC for binding of 9-27 oligo with hyperbranched DMAEMA are shown in Table 2 and the value for $\mathrm{K}_{\mathrm{obs}}$ is similar to those reported in the literature for binding of DNA by linear DMAEMA. ${ }^{22}$ On the other hand, the value of $\Delta H$ depends on both the enthalpy of condensation/complexation as well as the buffer conditions, since the measured enthalpy is also due to release of heat as a result of unprotonated DMAEMA abstracting a proton from the buffer in order to bind with the DNA. Thus, the $\mathrm{pH}$ at which the reaction is undertaken as well as the type of buffer that is used (buffer protonation enthalpy) will play an important role in the measured $\Delta \mathrm{H}$ and thus the measured enthalpy cannot be directly compared with literature values. ${ }^{22}$ The binding is driven by the favourable negative enthalpy associated with the electrostatic interaction, while there is a small contribution due to unfavourable negative entropy associated with condensation of the complex. 
Nonetheless, the binding appears to be driven by the larger enthalpic contribution due to electrostatic interactions. In addition, an endothermic process is observed just at the neutralization point (Figure 5a) and is probably related to structural re-arrangement of the highly branched molecule upon condensation with DNA. The zeta potential of the DNA:hyperbranched DMAEMA conjugates was measured as a function of N:P ratio, and these showed that upon titration of DNA into a solution of hyperbranched polymer at pH 5.5 (zetapotential of $+32.1 \mathrm{mV}$; Table 1, Entry1), the surface charge of the complexes changed from positive to negative with a neutral charge observed at a N:P ratio of approximately 1.1 (Table 1, Entry 1). Again, this suggests that neutralization of the negatively-charged phosphate groups in the DNA occurs upon addition of a slightly higher concentration of positively-charged amine groups.

a) P1

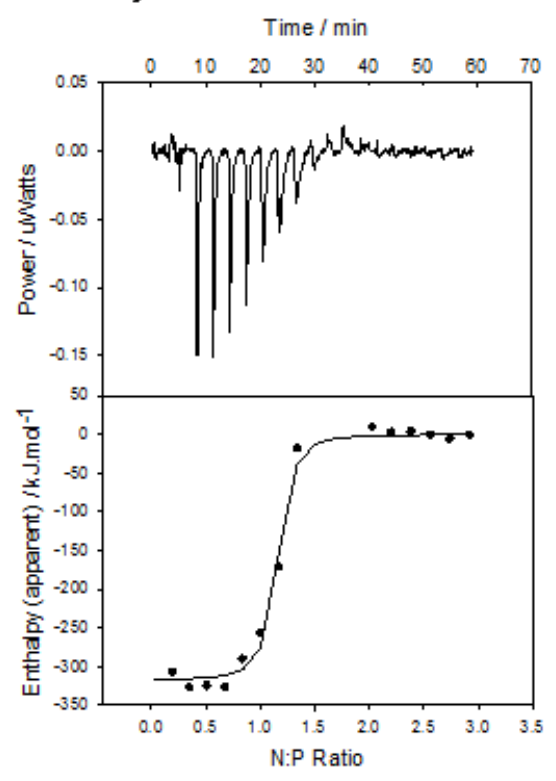

b) P2

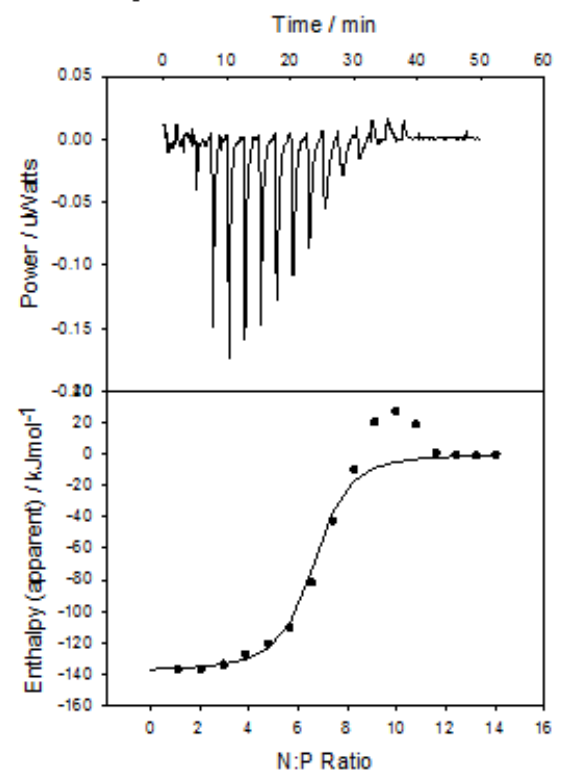

Figure 5. Isothermal calorimetry data for $\mathrm{P} 1(\mathrm{a})$ and $\mathrm{P} 2(\mathrm{~b})$ in $1 \mathrm{mM}$ phosphate buffer at $\mathrm{pH}$ 5.5. The raw data is fitted using the single site binding model and the thermochemical data are provided in Table 2 (two points at 32 and 35 minutes are removed from (a) to enable fitting).

The effect of PEGMA shielding on the polycation core was also investigated by ITC. Here, the number of cations required to reach binding equilibrium with DNA was found to be much larger (i.e. the N:P ratio at equilibrium binding was much higher) than that reported for $\mathrm{P} 1$. This is undoubtedly due to the 
enhanced shielding of the polycation core by the uncharged PEG shell and hence prevention of these cations to bind with the DNA. Interestingly, the binding isotherm for P2 shows a similar and significant endotherm just before equilibrium binding. This may be due to structural re-arrangement within the polymer upon condensation with the DNA. Nonetheless, the data was fitted to a single site model (full line in Figure 5b) in order to provide a qualitative comparison between P1 and P2 and the results are presented in Table 2. It is observed that upon chain extension of P1 with PEGMA (P2), the enthalpy of binding and the rate constant decreases (according to the single site model). Despite the inability for the single-site model to adequately explain the endotherm observed at just before binding equilibrium, the model could be used to qualitatively compare the N:P ratio at equilibrium binding. Clearly, the shielding of the cationic core means that a greater number of cationic species are required to bind with all of the phosphate groups on the DNA. This means that there is still a significant proportion of amine groups with positive charge within the hyperbranched polymer core.

Table 2. Thermodynamic parameters obtained from ITC for titration of P1 and P2 with DNA at pH 5.5.

\begin{tabular}{|l|l|l|l|}
\hline Polymer & $\mathrm{N}: \mathrm{P}^{\text {ratio }}{ }^{\mathrm{a}}$ & $\mathrm{K} / \mathrm{M}^{-1}$ & $\Delta \mathrm{H} / \mathrm{kJ} / \mathrm{mol}$ \\
\hline $\mathrm{P} 1$ & $1.1 \pm 0.01$ & $6.4 \times 10^{5} \pm 1.6 \times 10^{5}$ & $-326 \pm 7.16$ \\
\hline $\mathrm{P} 2$ & $6.58 \pm 0.08$ & $8.57 \times 10^{4} \pm 2.4 \times 10^{4}$ & $-137 \pm 3.13$ \\
\hline
\end{tabular}

${ }^{a}$ Error is due to data fit

The size and shape of the polymer:DNA complexes was investigated by AFM. In order to aid in observation of complexation behaviour, P1 and P2 were incubated with a $3 \mathrm{kbp}$ linear DNA at pH 5.5 and the resultant complexes observed after depositing onto a mica slide. Figure 6 shows the AFM images observed for P1 (a) and P2 (b) at N:P ratios of 1 and 10 (note, AFM images of DNA binding to P3 showed similar structures to those observed for P1). 
a)
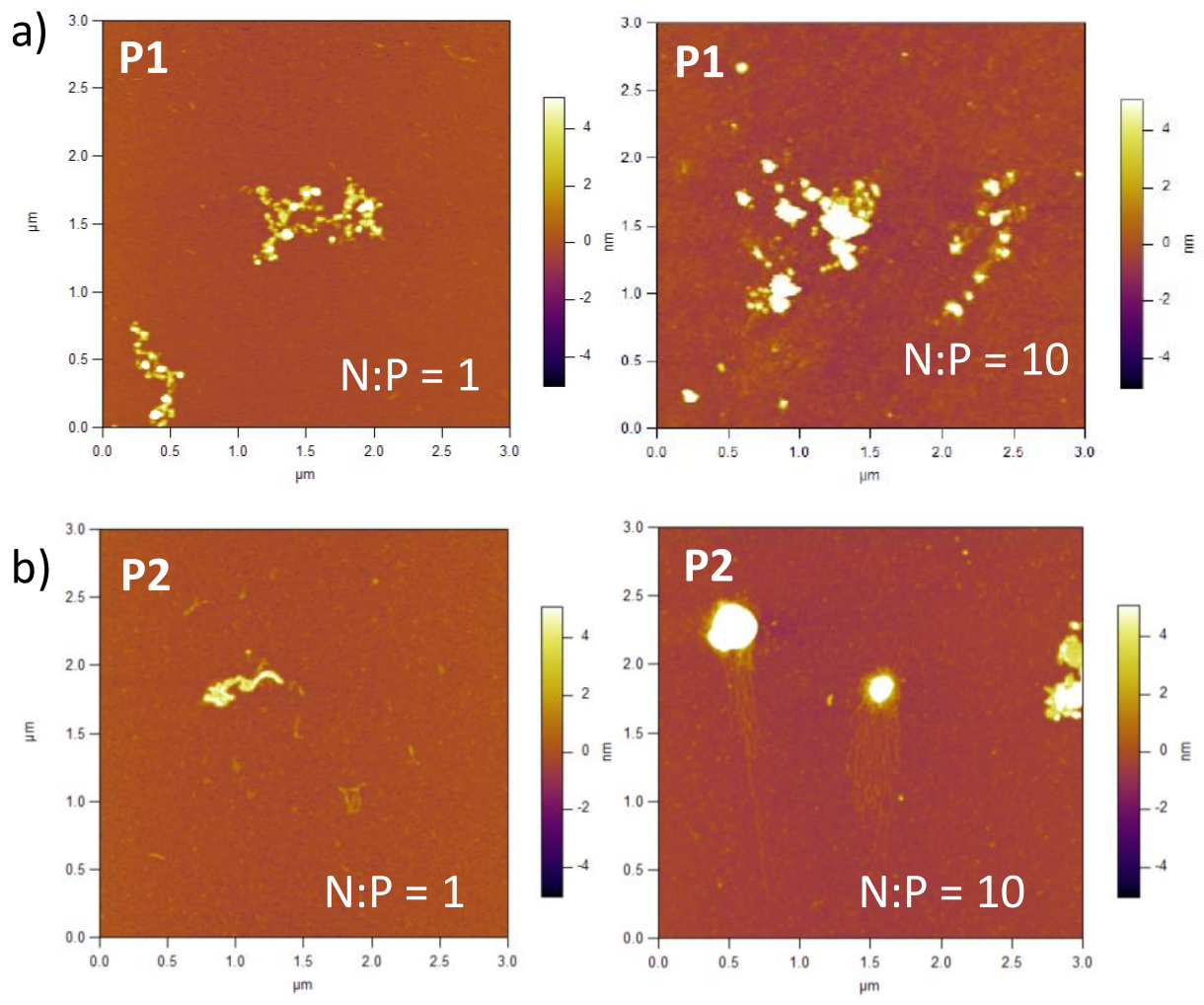

Figure 6. AFM images of polymer:DNA conjugates at pH 5.5 in 1 mM acetate buffer; P1 (a) and P2 (b) at specified N:P ratios.

Figure 6 shows bright spherical areas indicative of strong binding and complexation. There also exist areas within the image of free DNA strands, indicative of unbound DNA. The most obvious differences between the two classes of images are the degree of condensation that is observed. Clearly in the case of $\mathrm{P} 1$, relatively compact polymer-DNA conjugates are observed at $\mathrm{N}: \mathrm{P}$ ratios of 10 . At the lower $\mathrm{N}: \mathrm{P}$ ratio, binding is still observed but the conjugates exhibit much lower levels of condensation as is evidenced by the loosely-bound aggregates that are observed. This suggests that complete condensation of the DNA requires a higher concentration of polycation than the observed "neutralization" point measured in ITC or by zeta potential measurements. However, it should be noted here that the immobilization of the conjugates on the mica relies on electrostatic interaction between the polycation and the negatively charged mica surface. Thus, some of the cationic charges available for binding to DNA may be otherwise interacting with the surface. Aggregates in the size range of 100-200 $\mathrm{nm}$ are observed. 
Similarly, for the case of $\mathrm{P} 2$, at an N:P ratio of 1 , the DNA is not significantly condensed, however there is some evidence of complexation as shown by the aggregated regions within the linear DNA coil. However, uncomplexed DNA can also be observed in the AFM image at this ratio. When the N:P ratio is increased to 10, then large and compact conjugates are observed, however there appears to be trails of DNA emanating from the complex (the uni-directional alignment of these chains is due to washing artefacts). This suggests that binding and complexation is occurring, but that some unbound DNA may still be present and total condensation of the DNA has not yet been achieved. In this case, the complexes are in the size range of $200-400 \mathrm{~nm}$. The difference between the results observed for P1 and P2 is due to the shielding of cationic charge by the large PEGMA arms on the periphery of the hyperbranched DMAEMA particles and leads to much less efficient binding (based on a N:P ratio) - this effect was observed in both ITC and zeta potential measurements as well as in the gel-binding studies (described later).

To examine whether the size of the oligonucleotide has a significant effect on the size of the complexes that are formed, short chain oligo-DNA (9-27 Oligo) was used to mimic the size and characteristics of siRNA. Figure 7 shows a typical AFM image of the P1:oligo-DNA conjugate at pH 5.5 and an N:P ratio of 10. Clearly, the complexes are very compact and on a much smaller length-scale $(<50 \mathrm{~nm})$ than the analogous images observed for the larger and linear DNA (3 kbp) in Figure 5. Note that the height scale in Figure 6 is $2 \mathrm{~nm}$ as opposed to $10 \mathrm{~nm}$ in Figure 5. The much smaller size will significantly affect the pharmacokinetic properties of the complexes, for example, the kinetics of cell uptake as well as the rate and mechanism of clearance from the body. 


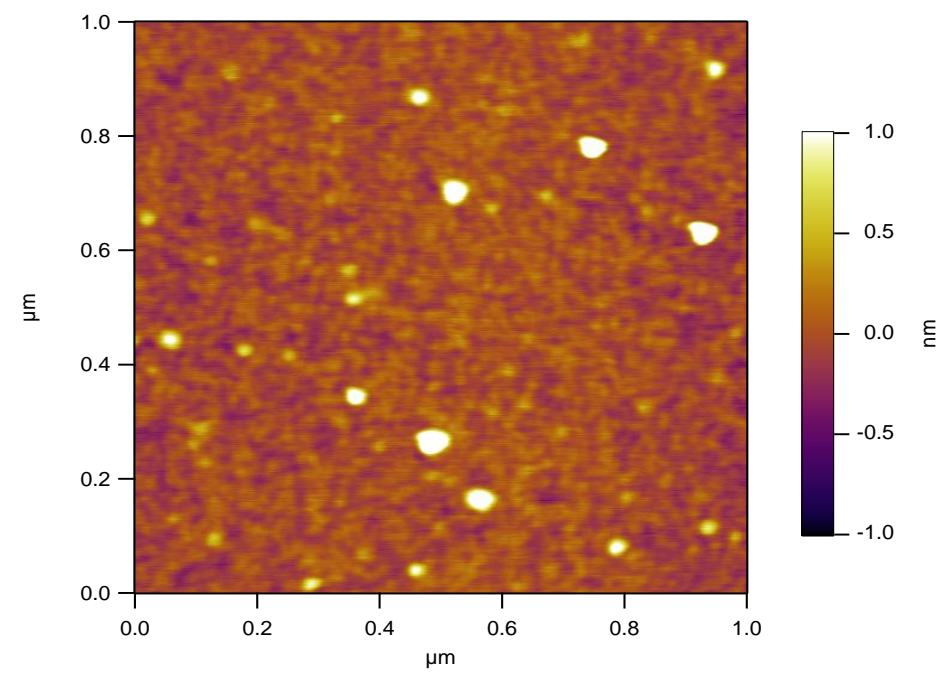

Figure 7. AFM image of P1:oligoDNA conjugates at N:P ratio of 10 . Note the small, compact and highly bound nature of the particles. The size is much smaller than that observed in Figure 5 for a larger DNA fragment (height scale is $2 \mathrm{~nm}$ compared to $10 \mathrm{~nm}$ in Figure 5).

Gel binding studies. Further evidence for complexation and binding of polycationic hyperbranched polymers and ODNs was obtained by gel electrophoresis studies. In this study, the 9-27 oligo was intercalated with ethidium bromide allowing visualization under UV light via the fluorescence signal. Upon addition of an electric potential across the gel, the negatively charged DNA migrates towards the positive electrode (top to bottom in Figure 8). Figure 8 shows the result of gel studies on P1, P2 and P3 and compares the migration through the gel to that of pure oligonucleotide $(\mathrm{N})$ and Oligofectamine $\mathrm{TM}^{\mathrm{TM}}$ (O). Oligofectamine ${ }^{\mathrm{TM}}$ is a commonly used transfection agent that can bind to oligonucleotides and so is a suitable benchmark agent for comparison.
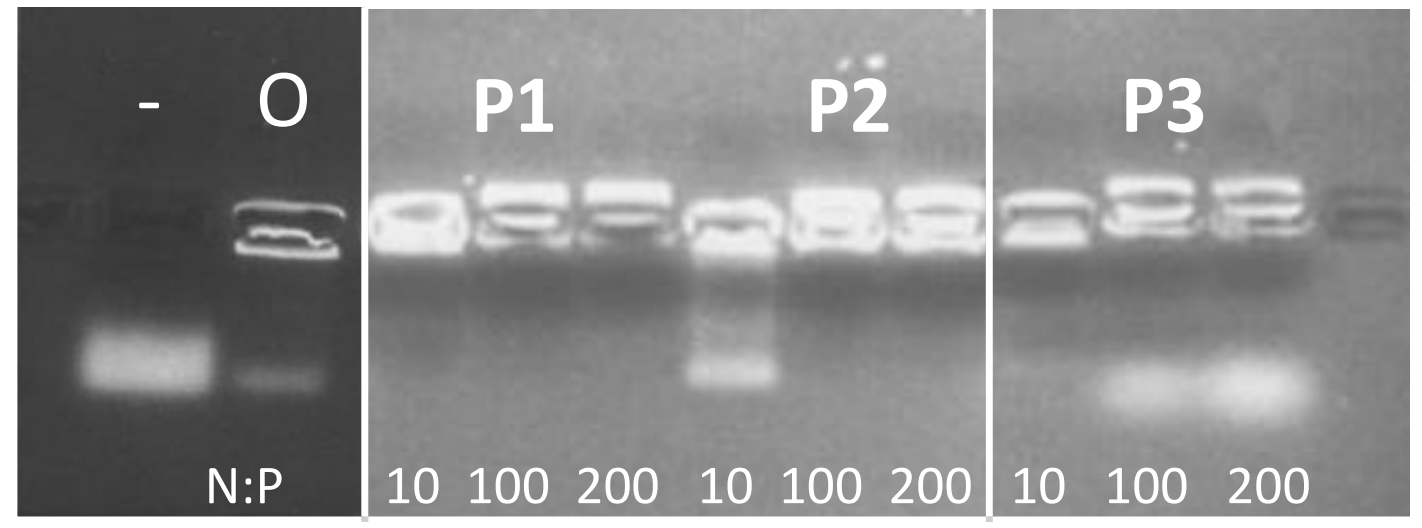

Complexed $\leftarrow$ Free DNA 
Figure 8. PAGE results for the hyperbranched polymers following incubation with oligoDNA at various $\mathrm{N}: \mathrm{P}$ ratios. $\mathrm{O}$ and $\mathrm{N}$ refer to DNA incubated in the presence of Oligofectamine and naked 9-27 Oligo in the absence of polymer, respectively. P1 and P3 show efficient binding at all N:P ratios while P2 shows efficient binding for $\mathrm{N}: \mathrm{P}>10$.

At all N:P ratios studied, the DNA is bound to P1 and does not migrate down the gel. This suggests that either the complex is too big to migrate out of the well, or the charge is neutral or positive at the ratios studied. The decreasing fluorescence intensity of the complex at higher hyperbranched polymer concentration suggests that the ethidium bromide is being excluded due to complexation of the DNA with the DMAEMA and the complex is seen to migrate up the gel (towards the negative electrode) at these higher polymer concentrations (due to the net positive charge of the complex at higher polymer concentration). In the case of $\mathrm{P} 2$, some DNA migration is observed at a N:P ratio of 10 (i.e. binding is not complete), but this is not observed for $\mathrm{N}: \mathrm{P}$ ratios $>10$ in this study. The decreased binding efficiency of P2 compared to P1 was also observed in the AFM images where much more loosely bound structures were observed, as well as the existence of free DNA in some cases. In addition, ITC and zeta potential measurements suggested that equilibrium binding of P2 with the DNA was not observed until N:P ratios were much higher than unity. This is undoubtedly due to shielding of the polycation core by the shell of the complexes. Furthermore, there may be a need for a much longer incubation time before running the gel in the case of P2 to facilitate molecular re-arrangement and maximum binding efficiency. In any case, the hyperbranched block copolymers, both native polycation (P1) and the pegylated analogue (P2), are able to complex effectively with DNA at higher, but still acceptable, N:P ratios. P3 showed similar binding attributes to that presented for P1 except that there is some evidence of free DNA at higher N:P ratios. An explanation for this may be that the folate is altering the spacing around the free binding groups, even though the charge and size of the molecule is similar to P1. However, we note in later discussion that protection from DNAse and transfection efficiency of P3 is still high.

\section{Oligonucleotide protection studies.}


The application of these hyperbranched polymers as siRNA carriers requires a polymer that can actively bind and protect the RNA from enzymatic attack. ${ }^{16}$ The polymer:DNA conjugates were incubated for 10 minutes followed by exposure to DNAse for 10 minutes at $37{ }^{\circ} \mathrm{C}$. At $\mathrm{pH} 5.5$, all polymers showed the ability to adequately protect the oligonucleotide from enzymatic degradation (supporting information Figure S1) presumably due to the strong "encapsulating" ability of the hyperbranched polymer as clearly shown in the AFM images.

\section{Transfection studies.}

In order to investigate the efficacy of delivery, uptake of the conjugates into HeLa cells was measured in vitro using complexes loaded with DNA oligos labeled with FITC and this was compared to a standard transfection agent, oligofectamine. Quantification of transfection was achieved by measuring the fluorescence of transfected cells using flow cytometry. Figure 8 shows comparative uptake of the polymer:9-27 oligo complexes (Figure 8a) as well as a comparison of the percentage of live cells following incubation to give an indication of cytotoxity (Figure 9b).

a)

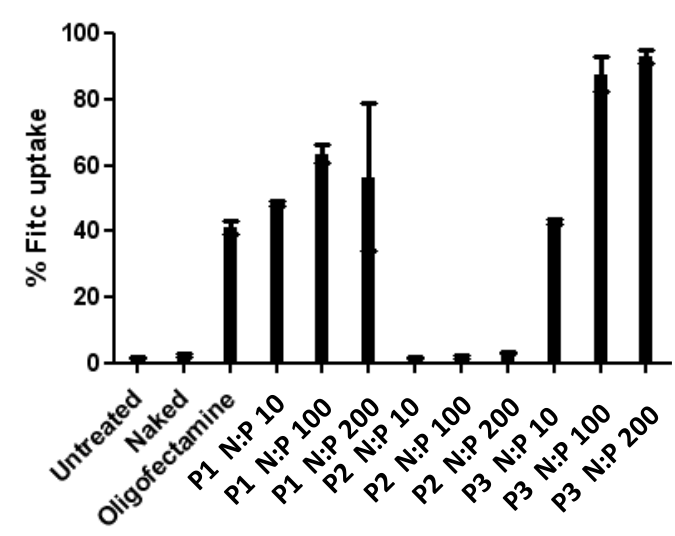

b)

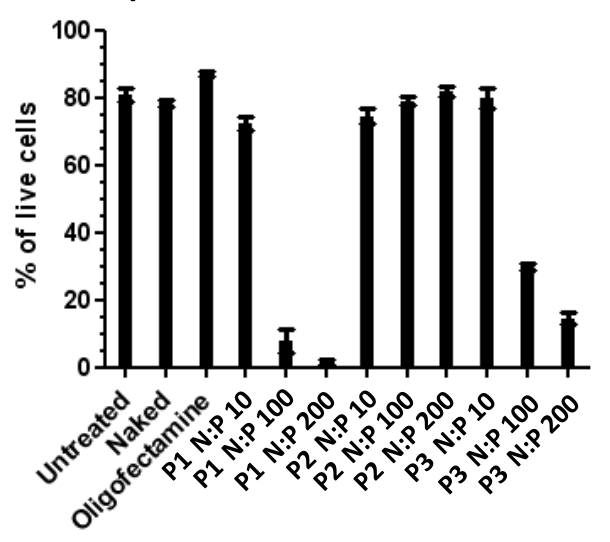

Figure 9. Cell uptake (a) and percentage of live HeLa cells (b) following uptake of polymer:oligo complexes at various ratios.

As expected, naked oligonucleotides show negligible uptake in vitro. P1 clearly facilitates equal, if not slightly increased, transfection of the oligonucleotide compared to Oligofectamine at all N:P ratios. However, when the N:P ratio is increased above 10, then significant cytotoxicity is observed for this 
polymer (Figure 9b). This is in agreement with previous work by our group and others and is attributable to the membrane disrupting properties of the polycation. ${ }^{15,18-19,23}$ While the pegylated polymer exhibits relatively minimal cytotoxicity compared to $\mathrm{P} 1$, the cell-uptake is low since the pegylation tends to "screen" the polymer from the cells and minimal interaction between cells and polymer is observed. ${ }^{24-26}$ Finally, P3 shows comparative cell uptake with P1 and oligofectamine for N:P ratio of 10 , but statistically significantly enhanced transfection is observed for $\mathrm{N}: \mathrm{P}$ ratios $>10$. This is undoubtedly due to the presence of folate ligands on the periphery of the hyperbranched polymer. HeLa cells overexpress the folate receptor ${ }^{27-29}$ and this enhances binding, and subsequent endocytosis, of the polyer:DNA conjugate. Unfortunately, when the N:P ratio is increased above 10, significant cytotoxicity is also observed, although not as severe as that observed for the pure polycation, P1. This suggests that the residual cationic charge on the polymer that is not bound to DNA binds with proteins on the cell surface which ultimately leads to cell death. Nonetheless, this shows that suitably designed hyperbranched polymers decorated with folate ligands can efficiently complex, condense, protect and deliver oligonucleotides intracellularly to HeLa cells in vitro, at least as efficiently as oligofectamine. In development of such a system, it is important then to consider the trade-off between cytotoxicity that may be observed and the enhanced transfection that is achieved by using folic acid a targeting ligand. It becomes clear from the results presented in Figure 9 that an N:P ratio between 1 and 10 will afford relatively low cytotoxicity, but facilitate enhanced transfection.

\section{Conclusions.}

In this paper, we have described the synthesis and characterization of hyperbranched DMAEMA polymers using RAFT chemistry that effectively bind and condense ODNs. While the pure polycation shows almost 1:1 binding ratio of $\mathrm{N}$ to $\mathrm{P}$ charges and effective binding and cell uptake comparable to oligofectamine is observed, significant cytotoxicity is observed at N:P ratios greater than 10 . When the polycation core is chain-extended with PEGMA using the pendent RAFT groups, cytotoxicity is reduced, however the polymer becomes less effective at condensing the DNA (as observed by AFM) at the lower $\mathrm{N}: \mathrm{P}$ ratios. At $\mathrm{N}: \mathrm{P}$ ratios $>10$, binding and condensation is observed and protection of the 
ODN against enzymatic degradation is clearly seen. However, little or no cell uptake is observed when the polycation is pegylated, presumably due to the so-called "stealth" properties of PEG. Finally, the polycation was decorated with folic acid using Huisgen dipolar click chemistry. The polycation that had folic acid attached to the particle exhibited similar properties to the base polycation, except much higher cell uptake was observed at the higher N:P ratios. This is presumably due to increased presentation of the folic acid ligands at higher polymer concentration allowing enhanced interaction with the overexpressed folic acid receptors on the cell surface of HeLa cells. Future work will involve determining the optimum chain extension length of PEGMA required to minimize cytotoxicity, while maximizing cell uptake through optimizing the level of folic acid conjugation.

ACKNOWLEDGMENT. The authors acknowledge funding from the Australian Research Council (KJT for DP0880032 andDP1094205), the Australian Institute for Bioengineering and Nanotechnology and the University of Queensland. NM acknowledges funding from the NHMRC and Cancer Council Queensland. The Australian National Fabrication Facility - Queensland node and Bogdan Danose are acknowledged for assistance with AFM and Dr Robert Falconer for assistance with ITC measurements.

Supporting Information Available. PAGE analysis of complex stability against enzymatic degradation. This material is available free of charge via the Internet at http://pubs.acs.org.

\section{Reference}

1. Hubbell, J. A., Science (Washington, DC, U. S.) 2003, 300 (5619), 595-596.

2. Read, E. S.; Armes, S. P., Chem. Commun. (Cambridge, U. K.) 2007, (29), 3021-3035.

3. Won, Y.-Y.; Davis, H. T.; Bates, F. S., Science (Washington, D. C.) 1999, 283 (5404), 960-963.

4. Thurmond, K. B., II; Kowalewski, T.; Wooley, K. L., J. Am. Chem. Soc. 1996, 118 (30), 72397240 .

5. Isaure, F.; Cormack, P. A. G.; Graham, S.; Sherrington, D. C.; Armes, S. P.; Buetuen, V., Chem. Commun. (Cambridge, U. K.) 2004, (9), 1138-1139.

6. Hawker, C. J.; Frechet, J. M. J.; Grubbs, R. B.; Dao, J., J. Am. Chem. Soc. 1995, 117 (43), 10763-4.

7. Frechet, J. M. J.; Henmi, M.; Gitsov, I.; Aoshima, S.; Leduc, M. R.; Grubbs, R. B., Science (Washington, D. C.) 1995, 269 (5227), 1080-3.

8. $\quad$ Guan, Z., J. Am. Chem. Soc. 2002, 124 (20), 5616-5617. 
9. Matyjaszewski, K.; Gaynor, S. G.; Kulfan, A.; Podwika, M., Macromolecules 1997, 30 (17), 5192-5194.

10. Rimmer, S.; England, R. M., Polymer Chemistry 2010, 1(10), 1533-1544.

11. Liu, B.; Kazlauciunas, A.; Guthrie, J. T.; Perrier, S., Polymer 2005, 46 (17), 6293-6299.

12. Liu, B.; Kazlauciunas, A.; Guthrie, J. T.; Perrier, S., Macromolecules 2005, 38 (6), 2131-2136.

13. Dasgupta, R.; Perrimon, N., Oncogene 2004, 23 (51), 8359-65.

14. Pack, D. W.; Hoffman, A. S.; Pun, S.; Stayton, P. S., Nat. Rev. Drug Discovery 2005, 4 (7), 581-593.

15. Thomas, M.; Klibanov, A. M., Appl. Microbiol. Biotechnol. 2003, 62 (1), 27-34.

16. Akhtar, S.; Benter, I. F., J. Clin. Invest. 2007, 117 (12), 3623-3632.

17. Deshpande, M. C.; Davies, M. C.; Garnett, M. C.; Williams, P. M.; Armitage, D.; Bailey, L.; Vamvakaki, M.; Armes, S. P.; Stolnik, S., J. Controlled Release 2004, 97 (1), 143-156.

18. Lv, H.; Zhang, S.; Wang, B.; Cui, S.; Yan, J., J. Controlled Release 2006, 114 (1), 100-109.

19. Thurecht, K. J.; Blakey, I.; Peng, H.; Squires, O.; Hsu, S.; Alexander, C.; Whittaker, A. K., J. Am. Chem. Soc. 2010, 132 (15), 5336-5337.

20. Lai, J. T.; Filla, D.; Shea, R., Macromolecules 2002, 35 (18), 6754-6756.

21. Kim, W.; Yamasaki, Y.; Jang, W.-D.; Kataoka, K., Biomacromolecules 2010, 11 (5), 1180 1186.

22. Rungsardthong, U.; Ehtezazi, T.; Bailey, L.; Armes, S. P.; Garnett, M. C.; Stolnik, S., Biomacromolecules 2003, 4 (3), 683-690.

23. Liu, Z.; Zhang, Z.; Zhou, C.; Jiao, Y., Prog. Polym. Sci. 2010, 35 (9), 1144-1162.

24. Yang, H.; Lopina, S. T.; DiPersio, L. P.; Schmidt, S. P., J. Mater. Sci. Mater. Med. 2008, 19 (5), 1991-1997.

25. $\quad$ Pasut, G.; Veronese, F. M., Adv. Drug Delivery Rev. 2009, 61 (13), 1177-1188.

26. Veronese, F. M.; Pasut, G., Drug Discovery Today 2005, 10 (21), 1451-1458.

27. Weitman, S. D.; Lark, R. H.; Coney, L. R.; Fort, D. W.; Frasca, V.; Zurawski, V. R., Jr.; Kamen, B. A., Cancer Res. 1992, 52 (12), 3396-401.

28. Sonvico, F.; Dubernet, C.; Marsaud, V.; Appel, M.; Chacun, H.; Stella, B.; Renoir, M.; Colombo, P.; Couvreur, P., J. Drug Delivery Sci. Technol. 2005, 15 (6), 407-410.

29. Sun, X. L.; Jayaram, H. N.; Gharehbaghi, K.; Li, Q. J.; Xiao, X.; Antony, A. C., Cancer Res 1999, 59 (4), 940-6. 


\section{$\underline{\text { TOC }}$}

Hyperbranched Polymers as Delivery Vectors for Oligonucleotides

Jian Hong Tan ${ }^{1}$, Nigel A. J. McMillan ${ }^{2}$, Elizabeth Payne ${ }^{2}$, Cameron Alexander ${ }^{3}$, Felicity

Heath $^{3}$, Andrew K Whittaker ${ }^{1}$ and Kristofer J Thurecht ${ }^{1}$ *

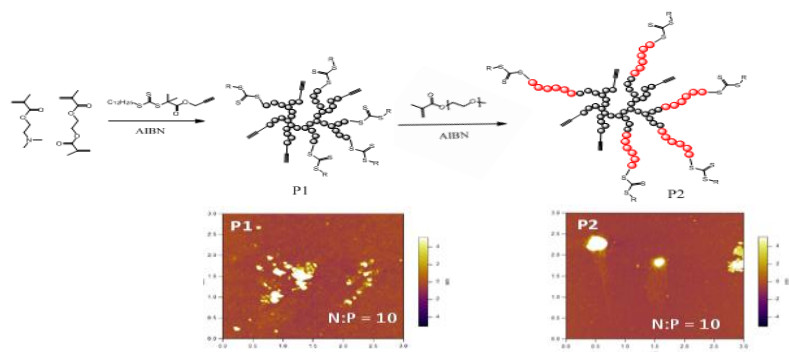

